\title{
Effectiveness of Mobile Learning as Disruptive and Innovative Strategy for Enhancing Quality Education at the University Level in Nigeria
}

* Sofowora Olaniyi Alaba (Ph.D)

\author{
Aina Samuel Ayobami \\ Adeleke Remilekun Lateef \\ Obafemi Awolowo University, Ile-Ife,Nigeria, Faculty of Education, \\ Department of Educational Technology and Library Studies Room 205 \\ oasofowora@yahoo.com/oasofowora@oauife.edu.ng
}

Doi:10.5901/jesr.2015.v5n1p55

\section{Abstract}

The study discussed numerous problems facing university education in Nigeria. It also described how M-learning can be used to resolve some of these challenges and how mobile platform can be used to distribute educational materials and remote tutoring to large students that enrolled for the Pre-Degree Programme of the Center for Distance Learning, Obafemi Awolowo University, Ile-Ife. The study used pretest post-test control group design. Sixty volunteered Mathematics students having mobile device with ready access to internet were used for the experiment. They were randomly assigned to experimental and control groups. Two research instruments used for the study were (i) the M-learning package designed using Moodle software consisting of nine steps and (ii) another termed Pre-Degree students perception inventory (PDSPI). The results showed that Mlearning was an effective innovative tool for teaching and learning. Similarly, students who were taught Mathematics using Mlearning found it very ease, useful and very engaging

Keywords: M-learning, disruptive innovations, mobility, distance education, Millennium Development Goals (MDGs) and virtual education

\section{Introduction}

The major concern all over the world is the provision of quality education to the teaming population. This concern was reflected in the Millennium Development Goals (MDGs) and UNESCO (2000) declaration: "Education for All". According to the MDGs, it is compulsory for every member nation to attain the following:

- $\quad$ ensure that all children particularly girls and children from educationally disadvantaged areas are provided with quality education,

- make sure that the learning needs of all the young children and adults are met in line with the MDCs;

- eradicate poverty and hunger; and

- $\quad$ achieve the Universal Basic Education (UBE) by 2015.

Sharing similar opinion is a 16years old activist, Malalah a Pakistani girl shot in the head by the Taliban in her address to the world during the United Nations Assembly recently, advocates that the whole world should harness all resources to provide quality education to the girls in the developing countries. It is not only in Pakistan that they are faced with the challenges of provision of quality education. Statistics have it that 35 million of the populations in Nigeria are illiterates. Not only this, $63 \%$ of the population is under 24 years with an annual growth rate of $3.24 \%$ (Clark and Ausukuya, 2013). Apart from the above, the CIA World Fact book put the number of universities in Nigeria in 2013 at 150 with an enrolment of $1,700,000$. At the primary school level the population of pupils was suppose to be 34.92 million while the actual is $24,682,000$. At the secondary school level,the actual enrolment was $9,057,000$. The above statistics shows that there are not enough schools to cater for students. The UNESCO (2012) Education for All Global Monitoring Report says one in five Nigerian children is out of school, making Nigeria the largest population of out of school children in the world. The This Day News paper of $19^{\text {th }}$ April, 2006 showed the disturbing admission challenges our youths are facing in getting admission into universities in Nigeria. In 2004/2005 Academic Session 838,051 applied only 261, 190 were offered admission. 2005/2006 session 908, 847 applied only 190, 392 were given admission, while in 2006/2007 session, 627,600 applied and only 205,170 were admitted .During the 2010/2011 session 1.3 million candidates applied 
and only 205,170 got admission The challenges of placement into Nigeria universities have led to high student mobility to outside Nigeria with its resultant impact on the Nigerian economy.

Table 1: UTME Applicants and Tertiary Admission 2004 - 2013

\begin{tabular}{cccc}
\hline $2004 / 2005$ & 916,878 & 122,492 & $14.5 \%$ \\
\hline $2005 / 2006$ & 916,371 & 76,984 & $8.4 \%$ \\
\hline $2006 / 2007$ & 803,472 & 88,524 & $11.0 \%$ \\
\hline $2007 / 2008$ & 911,623 & 107,370 & \\
\hline $2008 / 2009$ & 105,060 & & $12.5 \%$ \\
\hline $2009 / 2010$ & $1,182,381$ & 148,000 & $26.2 \%$ \\
\hline $2010 / 2011$ & $1,375,652$ & 360,000 & $26.8 \%$ \\
\hline $2011 / 2012$ & $1,493,609$ & 400,000 & $33.3 \%$ \\
\hline $2012 / 2013$ & $1,503,889$ & 500,000 & $31.1 \%$ \\
\hline $2013 / 2014$ & $1,670,822$ & 520,000 & \\
\hline
\end{tabular}

Source: World Education News (2013)

According to UNESCO Institute of Statistics (UIS), Nigeria rank next to Morocco with the highest international student mobility. As at 2010/2011 session, the number of Nigerians studying abroad was 39,851

Table 2: Nigerian Students Studying Abroad (2007 - 2010)

\begin{tabular}{ccccccc}
\hline \multicolumn{7}{c}{ Top Five Overseas Study Destinations } \\
\hline Year & First & Second & Third & Fourth & Fifth & Total \\
\hline 2010 & UK $(16,486)$ & USA $(6,510)$ & Malaysia $(5,443)$ & Ghana $(1,649)$ & Canada $(1,302)$ & 38,851 \\
\hline 2009 & UK $(14,380)$ & USA $(6,153)$ & Malaysia $(1,407)$ & Ghana $(1,349)$ & South Africa $(1,084)$ & 31,405 \\
\hline 2008 & UK $(11,783)$ & USA $(6,229)$ & Ghana $(1,349)$ & South Africa $(649)$ & Malaysia $(497)$ & 24,953 \\
\hline 2007 & UK $(11,136)$ & USA $(6,074)$ & Ghana $(1,349)$ & Germany $(430)$ & Canada $(405)$ & 22,712 \\
\hline
\end{tabular}

Source: UNESCO Institute of Statistics (UIS)

The mass exodus of our youths to countries like Canada, Malaysia, Ghana, United Kingdom and South Africa is an indication of crisis in the educational system in Nigeria. In recent times, Malaysia appears to be the most popular destination for Nigerians because of its low tuition attraction, attractive living condition and employment opportunity. The above has serious implication for the growth and development of our country Nigeria. In addition, statistics indicates that the total number of Nigerians studying in United States of Americas for first degrees, postgraduate courses and other professional training (OPT) from 2000 to 2012 is very high. Thus, we can also estimate the huge amount of money Nigerians used in developing the economy of other countries. Where as, some of the countries mentioned above have made use of virtual education under the platform of Open Distance Education Learning (ODEL). This explain why there is large influx of Nigerian students to these countries.

Table 3: Statistics Showing the Number of Nigerian Students in the United States

\begin{tabular}{cccccc}
\hline Year & Undergraduate & Graduate & OPT & Other & Total \\
\hline $2011 / 12$ & 3.577 & 2.522 & 819 & 110 & 7.028 \\
\hline $2011 / 11$ & 3,772 & 2,454 & 799 & 123 & 7.148 \\
\hline $2009 / 10$ & 3,498 & 2.327 & 646 & 97 & 6,568 \\
\hline $2008 / 09$ & 3.513 & 2.153 & 516 & 74 & 6.256 \\
\hline $2007 / 08$ & 3.745 & 1.968 & 438 & 71 & 6.222 \\
\hline $2006 / 07$ & 3.569 & 1.820 & 483 & 71 & 5.943 \\
\hline $2005 / 06$ & 4.102 & 1.819 & N/A & 271 & 6.192 \\
\hline $2004 / 05$ & 4.276 & 1.778 & N/A & 281 & 6.336 \\
\hline $2003 / 04$ & 4.287 & 1.680 & N/A & 173 & 6.140 \\
\hline $2002 / 03$ & 4.043 & 1.622 & N/A & 150 & 5.816 \\
\hline $2001 / 02$ & 3.059 & 1.308 & N/A & 132 & 4.499 \\
\hline $2000 / 01$ & 2.657 & 1.021 & N/A & 142 & 3.820 \\
\hline
\end{tabular}

*Source: World Education News 
Table 5: Top Fields of Study of Nigerian Students in the U.S.

\begin{tabular}{llclc}
\hline $2011 / 12$ & Engineering (22.7) & Business (16.3) & Health (14.3) & Life Science (12.5) \\
\hline $2010 / 11$ & Engineering (24.7) & Business (18.6) & Health (13.9) & Life Sciences (11.9) \\
\hline $2009 / 10$ & Engineering (23.6) & Business (19) & Health (14.2) & Life Sciences (11.8) \\
\hline
\end{tabular}

The fact that Nigerian youths prefer to travel abroad for further studies raises a serious question which must be critically looked into. It is therefore expedient that we need to carry out a critical study of how Malaysia, South Africa, United States, Canada and Ghana have transformed education in their respective countries. I am of the view that we should take cue from Malaysia and South Africa by leveraging on modern technology to leapfrog the education systems to eradicate poverty by the years 2015 . This can be achieved through virtual education with emphasis on Open Distance learning.

\section{Literature Review}

Mobile learning (M-learning) is a kind of learning that takes place via tablet, computers note pads, digital readers and portable hand sets. It involves the use of mobile devices to teach and learn. It can take place any where and any time responding to the needs of the society by providing learners with materials or resources they can access wherever and whenever they choose. M-learning can also be viewed as components of a learning programme or as add on tool. It is an innovation that creates a mud slide process or new market in the use of emerging technology in education (Fred, 2013). It is synonymous to multi-media learning, virtual learning or virtual education. As a disruptive force in education, it creates a new strategy that ultimately forced the former system to lower its cost and revolutionize the system (Christensen et-al 2006 and Eric 2007). Hence, in Nigeria context, embracing mobile technology and learning could be seen as a constructive and disruptive approach to resolving the current educational challenges. As a form of virtual education, the strategy can provide opportunity for students to receive direct instruction from a qualified teacher in an interactive environment. Students have direct and instant access to their instructor for instant feed back and direction. Also as a form of virtual learning, it provides a structured schedule of classes that can be helpful to students who find freedom of asynchronous learning to be overwhelming. It also encourages a social learning environment that replicate traditional classroom learning environment. Such class can be recorded and stored, a service that allow the students to instantly play back any topic missed out. It is also extremely useful for reviewing materials and concepts for upcoming examination. Parents are also provided with opportunity to monitor any classroom activity to ensure that they are satisfied with the education their ward is receiving. Commenting on the transformative power of mobile devices, Vmobile Nigeria (2007) says: "transaction which takes a whole week to conclude now get sorted out over mobile devices within minutes. People no longer have to take avoidable trip from one part of the city to other".

Mobile phones can actually keep tract of proceedings these explain why many advanced nations have taking advantage of these technology to provide distance learning programmes using the new disruptive innovation. It has been given different names depending on the level of development and technology. It is some times called virtual classroom, virtual education, on- line education, E-learning or M-learning. According to Guri-Rosemblit (2008) the different terminologies in literature is a reflection of the multiple roles they play in different settings and culture. Hence GuriRosemblit (2007) says the term is suffering from the "Tower of Babel Syndrome" i.e. a confusing language and misleading conclusion. In spite of the criticism against the adoption of mobile devices in learning in terms of engaging students away from learning and for cheating etc. I still think we can learn from other developed countries. Cohen (1996) is of the view that we can benefit from other countries by learning from their success and failure of attempted innovations. The authors there fore share the view of Cohen that we should have a deep understanding about specific research evidence and its interpretive transformation in educational settings of countries like South Africa, China, India, Malaysia and Israel. This is important because these countries have successfully used the virtual learning system to provide quality education through the Distance Education at a highly subsidized rate. According to UNESCO (2013) virtual education can facilitate scalable and sustainable educational reforms. It is against this background that this study was born out. The focus of the study is therefore specified below.

\section{Research objectives}

The following objectives were generated for the study: 
(i) design and develop an M-learning package on Mathematics for these set of students;

(ii) discuss the technology and platform that can be used to distribute educational materials and remote tutoring to the Pre-Degree students of the Centre for Distance Learning, Obafemi Awolowo University, Moro Campus;

(iii) discuss how mobile technologies can be used to distribute educational materials, support learning and enable remote tutoring among pre-degree students of the Obafemi Awolowo University, Distance Learning centre;

(iv) investigate the perception of the Pre-Degree students about the M-learning package in terms of ease of use, effectiveness and engagement.

\subsection{Motivation for this Work}

In sub-Saharan Africa and Nigeria in particular, educational systems are under stress it is estimated that 10 million primary school children are out of school even those that are fortunate to complete it often leave with literacy and numeracy skills far below the actual levels. In addition to this, is the shortage of trained and motivated teachers .Nigeria have against these significant odds made solid progress in improving its educational systems at all levels. However, the challenges are often too large. Yet there is a potential solution. While education is trying to cope, the communication industries through mobile communication have grown exponentially. Nigeria today is becoming the fastest growing and the second largest mobile phone market in Africa. The prevalence of mobile technologies in itself is a motivator and hence the need to exploit their usefulness in learning. According to Sharples, Chan, Rudman and Bull (2003) rather than seeing mobile devices as a disruptive device, educator should seek and exploit the potentials of the technologies children bring with them and find ways to put them into good use for the benefit of learning . Thus in Nigeria, it is assumed that mobile technologies can be effectively used to resolve the challenges faced in education using the distance learning approach.

\subsection{Conceptual Frame Work}

This study is guided by the theories of Vavoula and Sharples (2002) descriptive innovation, Technology Acceptance Model (TAM) by Sharples (2003), performance model (Vavoula, 2004) and constructivist learning. Vavoula and Sharples (2002) are of the opinion that the nature of learning is closely linked to the concept of mobility. Thus they suggest the following three ways by which we can learn. Learning is mobile in terms of space i.e. it happens at the work place, at home and at place of leisure. It is mobile between different areas of life, i.e. it may relate to work demands, self improvement or leisure and it is mobile with respect to time i.e. it happens at different times during the day on working days and on weekend (p.152). Constructivist approach sees learning as activities where learners actively construct new ideas or concept based on their previous and current knowledge in an active process. They are encouraged to be active constructions of knowledge. The Technology Acceptance Model of Davies (1989) was also used. It suggests that the student's intention to use any new innovation is based on the perceived usefulness (PU) and perceive ease of use (PEU). Thus TAM provides the frame work to determine the PU and the PEU of the Pre-Degree students of Obafemi Awolowo University, Center for Distance Learning Moro Campus to use the new innovative M-learning package in learning Mathematics. The suggestions of Pallof and Pratt(2003) and Pinantoon (2012) were also taking into consideration in the design of the m-learning package. They suggested that learning should be mobile at any time and any where (work place and leisure etc) in this age of globalization and changing economy, there is need to change the mode of education delivered, hence the need for mobile/ virtual learning which is a modern, more effective and batter ways of providing quality education.

\subsection{Materials and Methods}

This section discusses the research design adopted which is pre-test, post-test control group experimental design. The population is all registered pre-degree students of Center for Distance Learning, Moro-Campus of Obafemi Awolowo University, Ile-Ife .The sample is made of 60 volunteer students who have internet ready mobile devices and have signified their willingness to participate in the study

\subsection{Research Instrument}

A research instrument and a M-learning package constituted the instrument and material developed for this study. The 
M-learning package contained topics in the Pre-Degree Mathematics syllabus; the topics are Coordinate Geometry and Menstruations. It is designed using Moodle (study mate 25 install script set up launcher) and wamp server $2.2 \mathrm{~d}-\mathrm{x} 32$ wamp server 2 setup). The package is to be used as tutorial and practice an aspect that has been neglected in the universities due to lack of space, shortage of academic staff and fund. The M-learning model was developed using the Wireless Application Protocol Based Mobile Device. These are the essential steps in developing the contents of the Mlearning package:

Step1 prepare the topic using the micro soft word; (see the attached, fig 1)

Fig. 1: Prepare your content using your Microsoft word. There is a format for doing so. See example below:

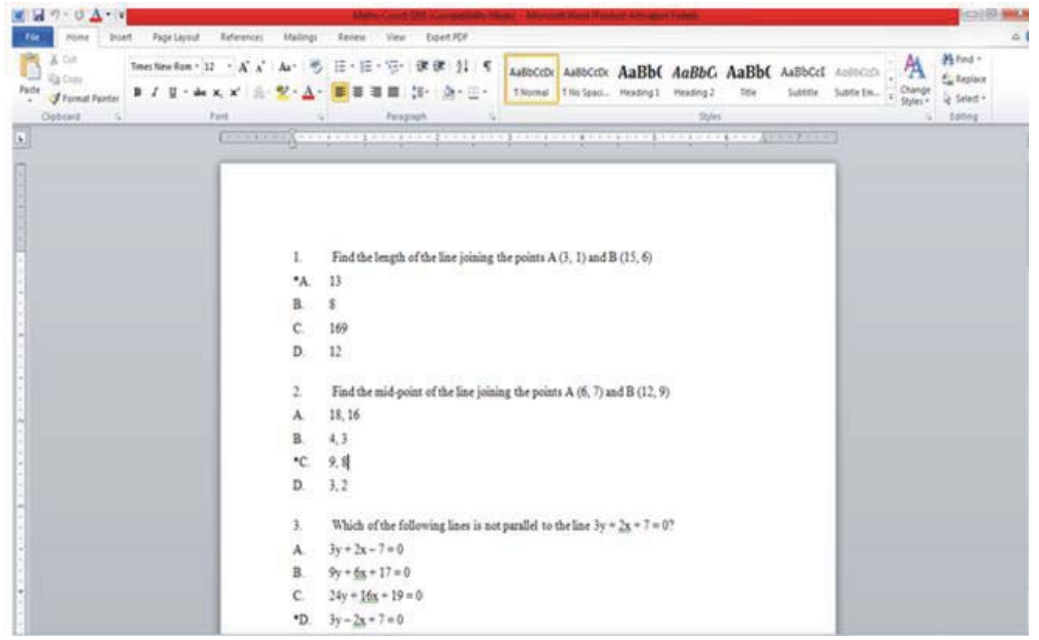

1. Find the length of the line joining the points $A(3,1)$ and $B(15,6)$
A. 13
B. 8
C. 169
D. 12

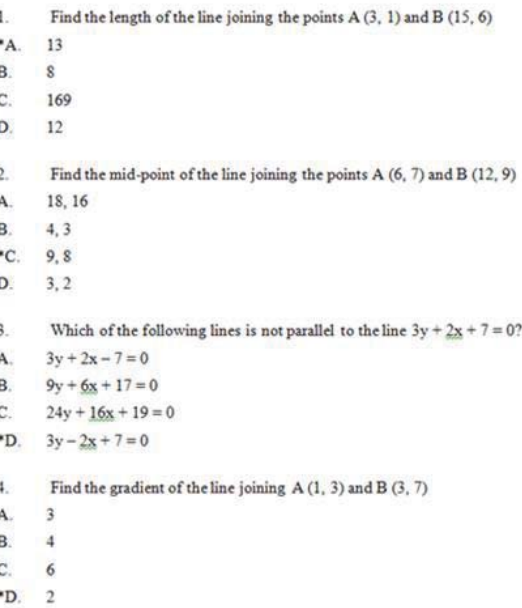

Step II organize the content into sets comprising the number of items you want the learners to have access to at a stretch (see the attached, fig 2) 
Fig 2

\begin{tabular}{|c|c|}
\hline ………… & 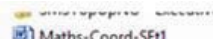 \\
\hline 4 Libraries & 지] Maths-Coord-SEt2 \\
\hline [. Documents & 직 Maths-Coord-SEt3 \\
\hline d) Music & 可) Moths-Coord-SEt4 \\
\hline$D$ Pictures & 8) Maths-Coord-SEts \\
\hline B Videos & 헤] Maths-Coord-Setr \\
\hline & ㅍ] Maths-Mensur-SEt1 \\
\hline Computer & [.] Maths-Mensur-SEt2 \\
\hline 国 Local Disk (C:) & 젬] Maths-Mensur-SEt3 \\
\hline Recovery (D:) & 함) Maths-Mensur-SEt4 \\
\hline GP_TOOLS(E) & [0] Moths-Mensur-SEt5 \\
\hline & 점 Maths-Mensur-SEt6 \\
\hline 甲 Network & (a) Maths-Mensur-SEt7.doc \\
\hline & ㅎ] Maths-Mensur-Set8.doc. \\
\hline & (D)] Maths-Mensur-SEt \\
\hline & 맘 Maths-Mensur-SEt10 \\
\hline
\end{tabular}

\begin{tabular}{|c|c|c|}
\hline . & $m$ & \\
\hline 4/10/2013 12:31 AM & Microsoft Word9... & $57 \mathrm{~KB}$ \\
\hline 4/25/2013 12:19 PM & Microsoft Word 9... & $76 \mathrm{~KB}$ \\
\hline 4/4/201312:35 PM & Mictosoft Word 9_. & $196 \mathrm{~KB}$ \\
\hline 4/3/2013 10:59 PM & Mictosoft Word9... & $64 \mathrm{~KB}$ \\
\hline 4/3/201311:15 PM & Microsoft Word $9 .$. & $281 \mathrm{~KB}$ \\
\hline 4/3/2013 11:44 PM & Microsoft Word 9... & $152 \mathrm{~KB}$ \\
\hline 4/10/2013 12:29 AM & Microsoft Word 9... & $126 \mathrm{kB}$ \\
\hline 4/10/20131:34 AM & Microsoft Word9... & $28 \mathrm{~KB}$ \\
\hline 4/10/20131:17 AM & Microsoft Word 9... & $97 \mathrm{~KB}$ \\
\hline 4/10/20131:30 AM & Microsoft Word9.. & $104 \mathrm{~KB}$ \\
\hline 4/13/20132.03 PM & Microsoft Word9... & $172 \mathrm{~KB}$ \\
\hline 4/13/20132:21 PM & Microsoft Word $9_{\ldots}$ & $176 \mathrm{~KB}$ \\
\hline 4/22/2013 7:40 AM & Microsoft Word D... & $14 \mathrm{~KB}$ \\
\hline 4/22/2013 7:42 AM & Microsoft Word D... & $15 \mathrm{~KB}$ \\
\hline 4/22/20137:44 AM & Microsoft Word D... & $16 \mathrm{~KB}$ \\
\hline & a. & \\
\hline
\end{tabular}

Step III : set up your respondus soft ware with which you will format your content and convert it into the zip folder format that moodle can understand. The purpose of the respondus is to make uploading easier once the approved format has been used. (See figure 3)

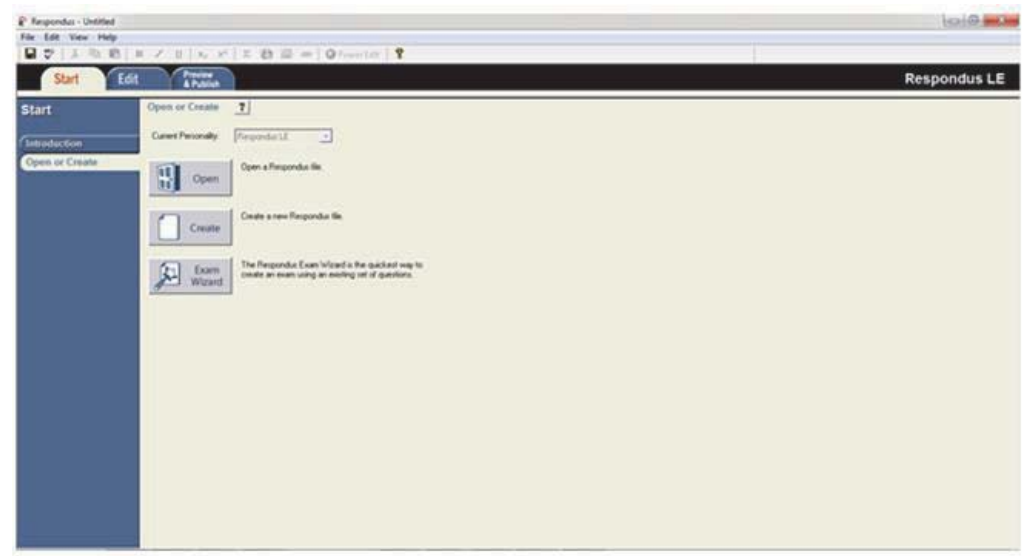

Upload your sets of questions into the Respondus or Study Mate Software to convert them into the format that moodle can understand:

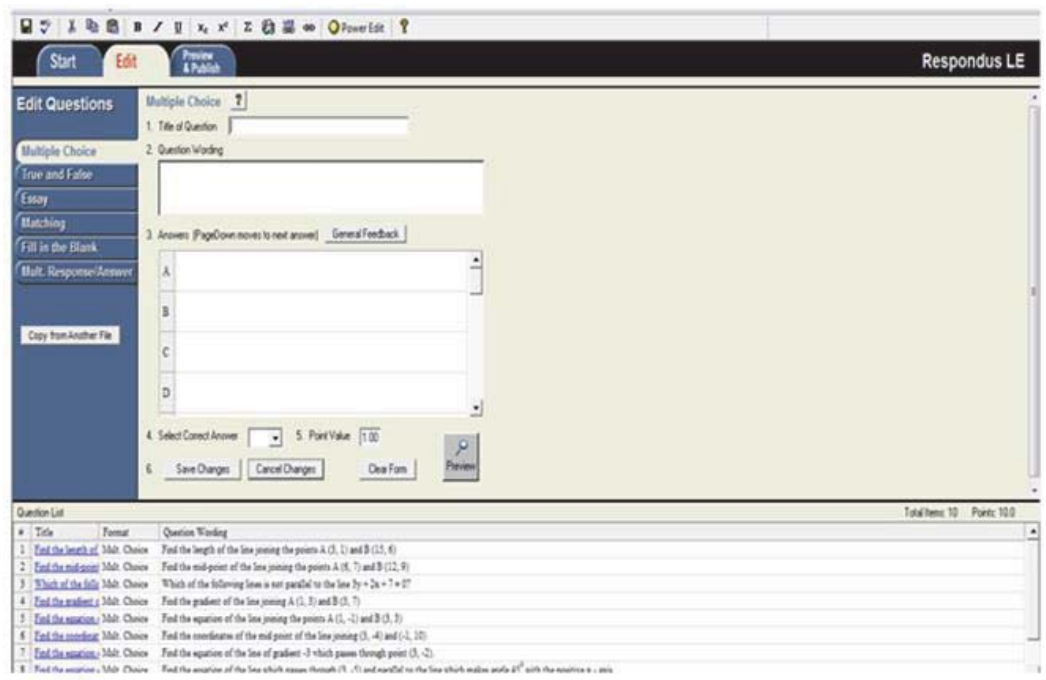


Step iv save each set of the topic with a unique name so that students can easily identity them on moodle as a separate set easily be acquired (see figure 4)

\section{Figure 4}

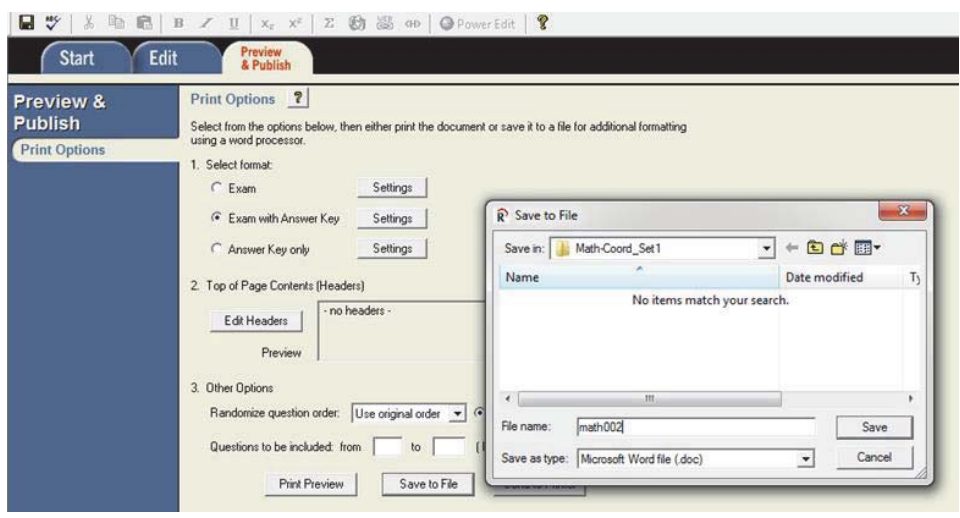

Below is an example of formatted questions saved with unique names in a given folder:

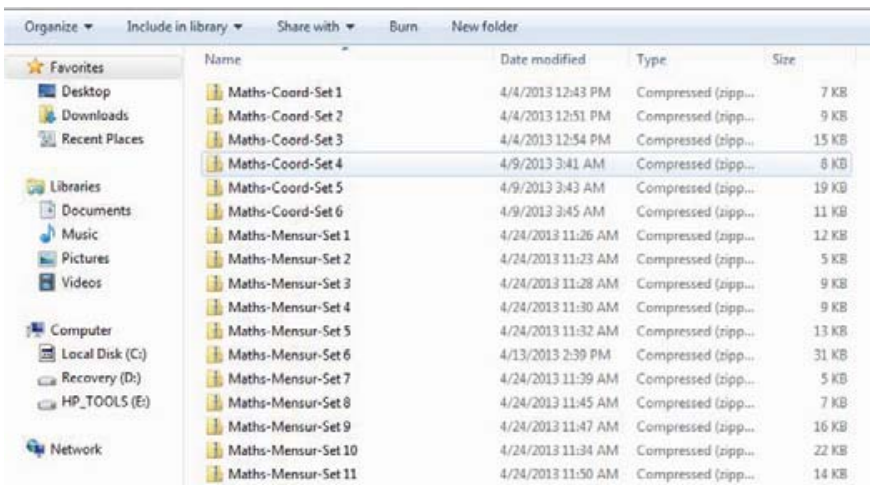

Step v install you moodle software and set it up either directly online via cpond on local horst and then upload it online using your filezilla. The process requires a little technical setup that can be acquired.(See figure 5)

\section{Figure 5}

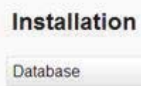

Database settings

\section{Improved MySQL (native/mysqli)}

Now you need to configure the database where most Moodle data will be stored. Database may be created if database user has needed permissions, username and password must already exist Table prefix is optional

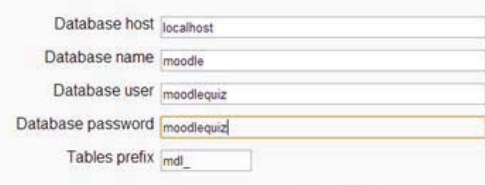

ePrenious Next $=$ 
Step vi the next stage is to choose an appropriate mobile responsive theme that students can easily get when they log on to the developed moodle site online. The mobile interface must bee attractive user friendly and be compressed to the size of the mobile phone screen of the students (see figure 6)

\section{Figure 6}

Tablet

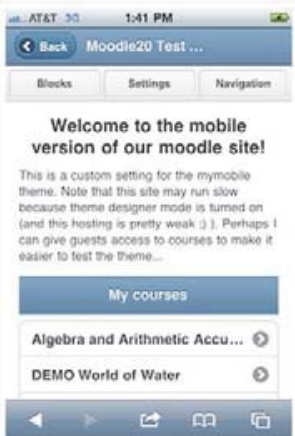

Step VII formatted content is then uploaded into the moodle platform already installed and working online. After which you identified the type of activity from the list of display (see figure 7)

\section{Figure 7}

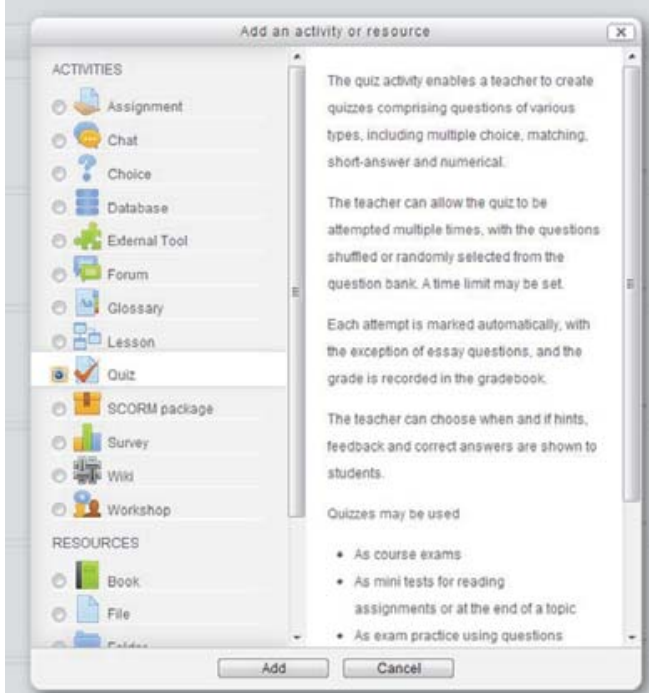

Select your platform.

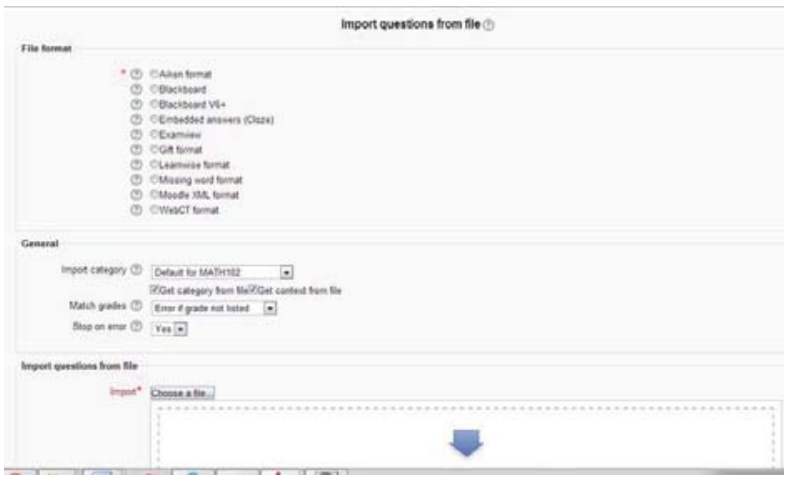


Then you import:

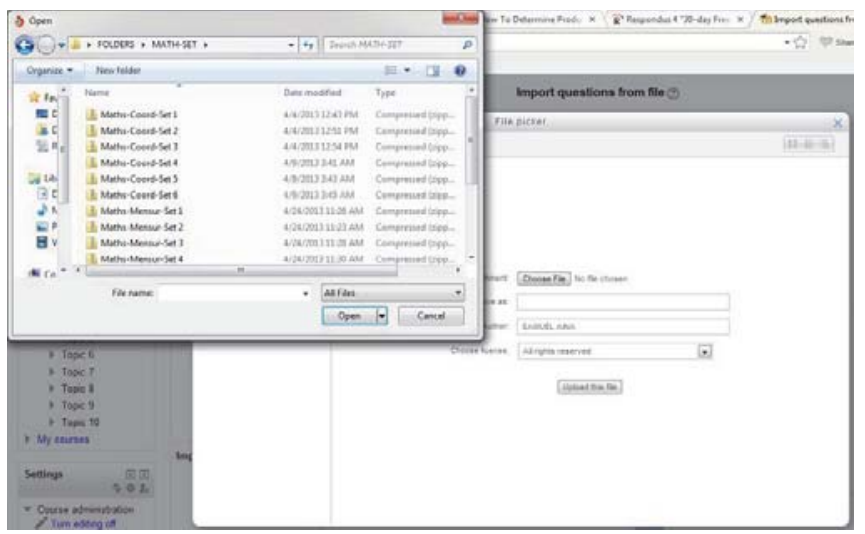

Step VIII Adjust the setting to suite your desire or expected outcome

Step IX test run your package to be sure that you get the desired or expected interface, behavior and performance.

The other instruments are (i) pre-Degree Students Perception Inventory (PDSPI) designed using 5 point Likert scale. It solicited for information from students about their perception for the M-learning in terms of benefits, ease of use, accessibility and effectiveness in engaging students. The package was used for the experimental group of 30 students while the control group was taught the same content using the conventional method. The PDSPI was later administered on the 30 participants in the experimental group.

The two instruments were validated by experts in the field of Mathematics, Educational Technology, Tests and Measurement and the students who were not part of the experiment. A reliability coefficient of 0.87 and 0.79 were obtained

\section{Data Analysis}

The data collected was analyzed using simple percentage, mean, standard deviation.

On the perception of the students about the effectiveness of M-learning, the following areas were assessed. (i) Acceptance, (ii) ease of use and (iii) engagement .

Table 6: Student's perception of the use of WAP Based Mlearning among OAU Ile-Ife Pre-Degree Mathematics Students

\begin{tabular}{lccccc}
\hline Sex & N & Sum & Xmean & Standard deviation & Variance \\
\hline & & 565.00 & 29.211 & 8.250 & 66.08 \\
(m) ease of use Engagement & 21 & 597.00 & 31.421 & 7.676 & 58.92 \\
& & 463.00 & 24.368 & 7.251 & 52.679 \\
\hline & & 211.00 & 30.143 & 6.986 & 48.810 \\
(f) ease of use Engagement effectiveness & 9 & 187.00 & 26.714 & 7.610 & 67.906 \\
& & 182.00 & 23.143 & 4.461 & 19.810 \\
\hline
\end{tabular}

From the table it can be deduced that male students perceived WAP-Based M-learning more useful for teaching mathematics than the female as male bad a means of 31.421 while female had 26.714. On the other hand, the situation was different for engagement. Female students $\left(X_{\text {mean }}=30.143\right)$ had higher engagement that their male counter part $\left(X_{\text {mean }}=29.211\right)$. However an assessment of the effectiveness of the package showed that it was effective in teaching Mathematics however there was no remarkable difference in their ratings (male $x=24.368$ and female $X_{\text {mean }}=23.143$ ). Hence one can conclude that WAP Based M-learning was very effective in presenting mathematics content. In addition, student perceived it very engaging and very useful 


\section{Conclusion}

It was concluded that mobile learning was an effective innovative tool for teaching and learning. In the same vein, the students who were taught Mathematics using the WAP-Based M-learn found it very easy, useful and very engaging. In addition, if effectively integrated it can be an effective strategy to stem down the high rate of Nigeria students mobility to outside for higher education.

\section{References}

Clark, N and Ausukuya, C (2013). An Overview of Education in Nigeria. World Education News Review, UNESCO Institute of Statistics (UIS)

Cohen, D (1996). Standard based school reform: policy, practice and performance. In H.F Ladd (Eds) Holding school accountable performance-based school reform in education Washington D. C. Brook ling Institution.

Cohen, D (2005). Speakers give outstanding view of academic caliber of Australian foreign students market. The Chronicle of Higher Education.

Christensen, C. N, Baumara, H.R, Saddler, T.M (2006). Disruptive Innovation for social change. Harvard Business School Press

Davis, F. A (1989). Perceived usefulness, ease of use and user acceptance of information technology. MIS quarterly 13 (3), $319-340$ http://dx.doi.org/10/2307/249008

Dun, J (2010). Mobile learning and what makes a great gap. Edudemic connecting education and technology

Eric, C (2007). The red pill of technology innovations. Red Pill

Fred, A (2013). How big data mobile technologies start-ups are changing education? http://www.opencollege.edu.au/infottrends/ howmobilelearning-expandingeudcation.

Guri-Rosenblatt, S (2010). Digital technologies in higher education, sweeping expectations and actual effect. Now science publishers inc. New York.

Guri-Rosenblatt, S (2007). Higher education in the, 21st century: seven pairs of Contrastim trends. In J. Enders and F, Van Vaught (Eds) towards a cartography of higher education policy charge. University of twente center of Higher education policy study $18,5-29$ http.//dx.doc.org/1057palgrave.hep.8300069

Marshall, J. (2013). International students mobility report. World Education News UNESCO.

Palloff, R. M and Pratt K (2003): The Virtual student: A profile and guide to working with online learners. San Franscisco Jossey-Bassey

Pinantoon, A (2012): How mobile learning is expanding educational reach. Htt.p//www.opencollege.edu.au.into.edu.tiends.howmobilelearning-expandingeducation-reail/\#ixzz2hzbs0c13.

Sharpes, M.(2003). Disruptive devices: mobile technology for conventional learning International Journal of Continuing Engineering Education and Life Long Learning 12 (516). 504-520.

Sharpes ,M, Chan ,T. Rudman, P. and Rule, S. (2003). Evaluation of mobile learning organizer and concept mapping tools. Proceedings of MLEARN 2003 learning with mobile devices, London UK. Learning and skill Development Agency 139-144.

Vavoula, G (2004). Kleas: knowledge and learning organization system in support life long learning. Ph.D Thesis. The University of Birmingham

Vavoula, G. and Sharpes, M. (2002). Kleas: a personal mobile, knowledge and learning organization system. In . M. Hoppe and U. Kinshak (eds) Proceeding of the IEEE international workshop on mobile and wireless technologies in education (WMIE 2002) Vaxjo, Sweeden 152-156. 